\title{
Roflumilast: the fourth Mousquetaire in COPD pharmacological treatment
}

\author{
Bruno Balbi ${ }^{*}$
}

Monaldi Arch Chest Dis 2013; 79: 3-4, Suppl., 3-6.

Keywords: COPD, Pharmacological treatment, LABA, LAMA, ICS, Roflumilast.

1 Pulmonary Rehabilitation Department, I.R.C.C.S. "Salvatore Maugeri” Foundation, Veruno (NO), Italy.

Correspondence: Dr. Bruno Balbi, MD, PhD, Pulmonary Rehabilitation Department, I.R.C.C.S. "Salvatore Maugeri”Foundation, Via Revislate 13,28010Veruno(NO),Italy; e-mail: bruno.balbi@fsm.it

As a middle-aged Pulmonary Physician, I am well aware of the progress made over the past couple of decades in the pharmacological treatment of chronic obstructive pulmonary disease (COPD). In the eighties, specific treatments for patients with COPD were based on short-acting bronchodilators, mainly beta-agonists (SABAs), namely salbutamol and theophylline. Long-term treatment was thus based mainly on theophylline per os, with SABAs as bronchodilators, but, due to their pharmacological properties, they were mainly used on demand.

Today, the cornerstones of pharmacological treatment of stable COPD are long-acting bronchodilators, both beta-agonist and anticholinergic muscarinic antagonists (LABAs and LAMAs) and inhaled corticosteroids (ICS). Is this therapeutic armamentarium sufficient to cater for our needs and for the needs of our patients? No doubt the an- swer is no. Or better, for a large proportion of patients these pharmacological treatments, either alone or more frequently combined, are sufficient to reach if not completely almost entirely the goals of an effective and comprehensive treatment of COPD, as the "Global Initiative for Chronic Obstructive Lung Disease" (GOLD) guidelines state [1]. Nevertheless, this is the "easy" part of the treatment of COPD, probably reflecting the management of the initial, less complicated stages, after smoking cessation, enforcement of educational approaches and compliance strategies together with treatment of the first acute exacerbation of COPD (AECOPD) episodes. The difficult part of COPD treatment starts when all the initial, easy-to-understand and to put-in-practice steps have already been performed, yet the patient is not doing well: symptoms, namely dyspnea and cough, are still limiting the daily life activities of the pa-

The work originated from the Pulmonary Rehabilitation Department, I.R.C.C.S. "Salvatore Maugeri" Foundation, Via Revislate 13, 28010 Veruno (Italy), and has been supported by a grant from Takeda Italia SpA.

* This author received a consultancy fee by Takeda Italia SpA for critical evaluation of the clinical cases and of the review present in this issue.

Editorial assistance was provided by Selene Mogavero, PhD and Colin G Egan, PhD (Primula Multimedia SrL) and was sponsored by Takeda Italia SpA. 
tient, AECOPD episodes increase in frequency, as well as severe respiratory failure episodes, which initially may be only during physical exercise, later on also at rest.

What can we do in these type of patients? As Head of a Pulmonary Rehabilitation (PR) Department I also believe in non pharmacological approaches for patients with COPD. PR is usually effective in reducing symptoms, improving exercise capacity, reducing rate and severity of AECOPD episodes and improving the quality of life of these patients [2]. Yet, the management of COPD should integrate pharmacological and non pharmacological approaches, in a scenario in which one approach does not exclude the other, rather one can potentiate and maximize the effects of the other approach [1].

Thus, coming back to pharmacological treatment of COPD, how can we fight the battle of the "difficult" COPD patients? Perhaps the XIX Century French literature can help us in this task.

Athos, Porthos, and Aramis were Les Trois Mousquetaires in the famous novel by Alexandre Doumas father. They were very successful and served the King of France. However, they knew they could be even more powerful if only the three Mousquetaires were... four! And then D'Artagnan came over and joined the three as the fourth one. No wonder that the four together were able to win all the fights and battles and to protect the Kingdom of France from all kinds of threats.

Could this be the case also for roflumilast? Could roflumilast help the other three Mousquetairs (LABA, LAMA and ICS) solving the difficult problems at least in a fraction of patients with COPD? No doubt, we hope this is the case.

There are data suggesting this type of consideration, at least for a subtype of patients. Many studies, including randomized clinical trials (RCT), were performed to show the effects of roflumilast and to register the drug in international markets [3-14]. They demonstrated that the new drug is effective in the chronic bronchitis phenotype of COPD, particularly in those with frequent and recurrent AECOPD episodes. But the hardest task for any new drug is the real life clinical practice. And this is especially true for a new class of drugs in respiratory disorders, as phosphodiesterase-4 (PDE4) inhibitors.

This issue of Monaldi Archives is dedicated to real life reports of the use of roflumilast in clinical practice. After a comprehensive review on the drug and its clinical data [15], six reports from different Hospitals and groups across Italy describe similar stories [16-21]. The reports deal with patients with recurrent AECOPD episodes causing multiple hospitalization (so called "revolving door patients"), patients not responding to conventional treatments, with accelerated decline of lung function, multiple comorbidities, developing disability. In a word "difficult" patients in which all the logical and easy steps in pharmacological treatment of COPD have been put in place without convincing and effective results.

In these patients, the appearance of roflumilast on the horizon really seems to make the difference, to change the history of the disease, to help the patients do better and to restore previously seen clinical conditions, with a real "journey in times", resetting the clock to stages of the disease that the patients were experiencing many months (perhaps even years?) before.

How can this happen? We believe that we are just at the beginning in our understanding of the mechanisms of action of roflumilast, of which only few are now known. Interactions with other classes of drugs employed in COPD patients are suggested by some of the present reports and probably this is at least in part the reason for the examples in which roflumilast is able to significantly improve patients' health status.

We at Monaldi Archives understand the limits of anecdotal medicine, particularly when opposed to evidence based medicine. 
This is not our case. These reports reinforce the data obtained in RCTs and incorporated in guidelines as they were judged solid and convincing [1]. Thus, the reports comprised in this issue of Monaldi Archives may be seen as an opportunity for clinicians to re-think treatment of COPD. Maybe when all the available drug classes are already part of the treatment of COPD in a patient, yet he or she is not doing well, maybe there is an additional chance, a secret weapon, a wild card to be played on the game table. This can be seen as a fourth Mousquetaire, the one that makes the difference between a lost and a won battle. Its name is not D'Artagnan, but roflumilast.

\section{References}

1. Global Initiative for Chronic Obstructive Lung Disease (GOLD). Global Strategy for the Diagnosis, Management and Prevention of COPD. 2013. Available at www.goldcopd.org.

2. Spruit MA, Singh SJ, Garvey C, et al. An official American Thoracic Society/European Respiratory Society statement: key concepts and advances in pulmonary rehabilitation. Am J Respir Crit Care Med 2013; 188: e13-64.

3. Lipworth BJ. Phosphodiesterase-4 inhibitors for asthma and chronic obstructive pulmonary disease. Lancet 2005; 365 (9454): 167-175.

4. Bethke TD, Böhmer GM, Hermann R, et al. Dose-proportional intraindividual single- and repeated-dose pharmacokinetics of roflumilast, an oral, once-daily phosphodiesterase 4 inhibitor. J Clin Pharmacol 2007; 47: 26-36.

5. Rabe KF. Update on roflumilast, a phosphodiesterase 4 inhibitor for the treatment of chronic obstructive pulmonary disease. Br J Pharmacol 2011; 163: 53-67.

6. Grootendorst DC, Gauw SA, Verhoosel RM, et al. Reduction in sputum neutrophil and eosinophil numbers by the PDE4 inhibitor roflumilast in patients with COPD. Thorax 2007; 62: 1081-1087.

7. David M, Zech K, Seiberling M, et al. Roflumilast, a novel, oral, selective PDE4 inhibitor, shows high absolute bioavailability. Journal of Allergy and Clinical Immunology 2004; 113 (2, Supplement): S220-S221.

8. Nassr N, Huennemeyer A, Herzog R, et al. Effects of rifampicin on the pharmacokinetics of roflumilast and roflumilast $\mathrm{N}$-oxide in healthy subjects. Br J Clin Pharmacol 2009; 68: 580-587.

9. Giembycz MA, Field SK. Roflumilast: first phosphodiesterase 4 inhibitor approved for treatment of COPD. Drug Des Devel Ther 2010; 4: $147-158$.

10. Agusti A, Calverley PMA, Celli B, et al. Characterisation of COPD heterogeneity in the ECLIPSE cohort. Respir Res 2010; 11: 122.

11. Bateman ED, Rabe KF, Calverley PMA, et al. Roflumilast with long-acting $\beta 2$-agonists for COPD: influence of exacerbation history. Eur Respir J 2011; 38: 553-560.

12. Fabbri LM, Calverley PMA, Izquierdo-Alonso $\mathrm{JL}$, et al. Roflumilast in moderate-to-severe chronic obstructive pulmonary disease treated with longacting bronchodilators: two randomised clinical trials. Lancet 2009; 374 (9691): 695-703.

13. Calverley PMA, Sanchez-Toril F, McIvor A, et al. Effect of 1-year treatment with roflumilast in severe chronic obstructive pulmonary disease. Am J Respir Crit Care Med 2007; 176: 154-161.

14. Rennard SI, Calverley PMA, Goehring UM, et al. Reduction of exacerbations by the PDE4 inhibitor roflumilast - the importance of defining different subsets of patients with COPD. Respir Res 2011; 12: 18.

15. Zanini A, Cherubino F, Pignatti P, Spanevello A. The use of roflumilast in COPD: a review. Monaldi Arch Chest Dis 2013; 79 Suppl: 7-18.

16. Bonini M, Palange P. Roflumilast is safe and effective in improving symptoms and lung function in severe COPD. Monaldi Arch Chest Dis 2013; 79 Suppl: 19-22.

17. Carraro CF. Two cases of COPD benefitting from therapy with roflumilast. Monaldi Arch Chest Dis 2013; 79 Suppl: 23-28.

18. Guarnieri G. Roflumilast succeeds where traditional therapy fails: a report of a case of moderate COPD. Monaldi Arch Chest Dis 2013; 79 Suppl: 29-34.

19. Parola D, Castagnacci A, Salvati S. A case report of roflumilast in an elderly COPD patient: improving exercise capacity to improve quality of life. Monaldi Arch Chest Dis 2013; 79 Suppl: 35-40.

20. Polla B. Roflumilast is effective in reducing COPD related exacerbations and improving CAT score. Monaldi Arch Chest Dis 2013; 79 Suppl: 41-44.

21. Sposato B. Significant gas-exchange improvements reported after roflumilast in two cases of severe COPD. Monaldi Arch Chest Dis 2013; 79 Suppl: 45-48. 


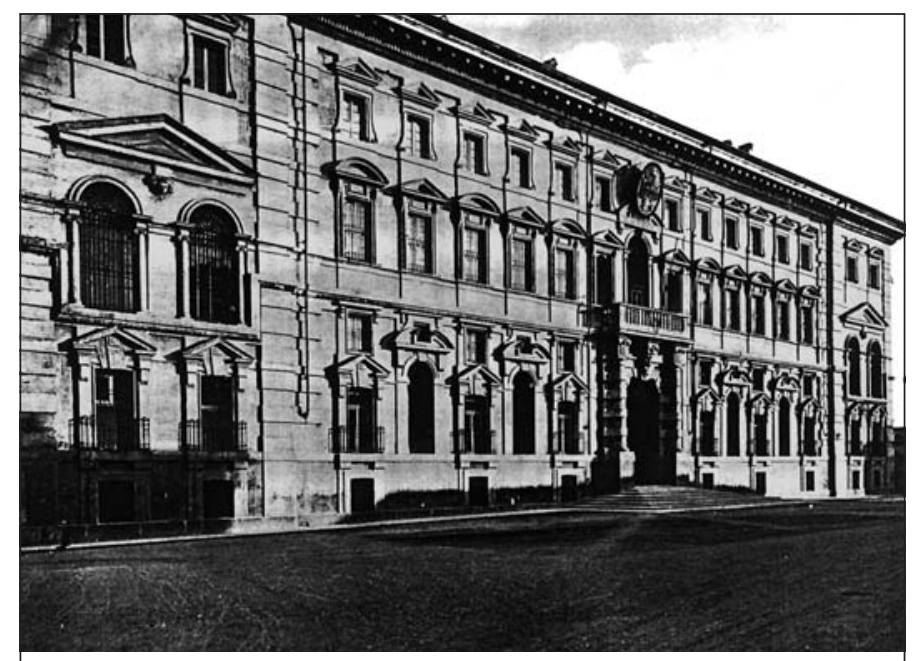

Pavia - Almo Collegio Borromeo 